\title{
VIOLÊNCIA E PROMOÇÃO DA SAÚDE
}

Constance Rezende Bonvicini Jean Carlos da Silva ${ }^{6}$

\section{RESUMO}

Este artigo é resultado de um estudo sobre as formas de violência e a promoção da saúde na sociedade contemporânea. A escolha da temática ocorreu pelo interesse em compreender-se sobre aspectos da violência a luz das propostas de prevenção oferecidas pela política da promoção da saúde. O estudo realizado através de revisão bibliográfica utilizou-se de dados retirados de artigos científicos, realizando-se um levantamento virtual das produções acadêmicas por meio de bases de dados científicos confiáveis como: Lilacs, Bireme e Scielo. Concluiu-se com esta pesquisa que várias são as formas de ação violentas, mas que é possível planejar estratégias de promoção da saúde para o enfrentamento deste mal social.

\section{ABSTRACT}

This article is the result of a study on forms of violence and the promotion of health in contemporary society. The choice of the theme was the interest in understanding on aspects of violence the light of the proposals offered by prevention of health promotion policy. The study based on a review we used data taken from scientific articles, making it a virtual survey of academic activities by reliable scientific databases such as Lilacs, Bireme and Scielo. The conclusion of this research was that there are several forms of violent action, but it is possible to plan health promotion strategies for the fight against this social evil.

Keywords: Violence. Types of Violence. Health promotion.

\section{INTRODUÇÃO}

A violência, seja qual for sua manifestação, é sempre uma derrota à dignidade da vida, à liberdade do ser humano. Há o crescimento desenfreado da incidência da violência em escala global, impactando diretamente a vida das pessoas e das coletividades. Notoriamente, reconhece-se que

\footnotetext{
${ }^{6}$ Endereço eletrônico de contato: constancebonvicini@yahoo.com.br
}

Volume 1, Número 1 - Abril, 2015. 
se trata de um problema de saúde pública, tendo em vista que seu conceito diz respeito a qualquer ato que comprometa a integridade física ou psicológica, causando danos a quem sofre. ${ }^{(1)}$

A violência como violação de direitos e expressões variadas em diferentes contextos destaca a desigualdade de direitos e os conflitos sociais acentuados no Brasil, onde é notório o crescimento das taxas de violência nas suas mais distintas modalidades. O crime comum, violência fatal conectada com o crime organizado, graves violações de direitos humanos, explosão de conflitos nas relações pessoais e intersubjetivas, e em especial, crimes contra crianças, adolescentes, crime contra a mulher e contra o idoso, e a emergência do narcotráfico, tem grande parte de sua responsabilidade na construção do cenário de insegurança coletiva. ${ }^{(2)}$

Existem muitas formas de resolução de conflitos, dentre as quais o mecanismo punitivo institucionalizado. Percebendo-se que tal prática punitiva é vista como uma possibilidade de transformação do indivíduo através da ressocialização. Por outro lado, tornaram-se medidas por vezes inconsequentes e causadoras de desordem social. Tal prática é ainda, percebida pela sociedade como influente nas formas de prevenção ao delito, bem como um dos tratamentos dado ao problema. ${ }^{(3)}$

Nos diversos tipos de violência, em que se incluem desde a violência física contra a criança, adolescente, idoso, mulheres até a violência psicológica, são partes do objeto de estudo deste artigo. Nele, será definido o conceito de violência e o da promoção da saúde e, como objetivo geral, verificarse-á como a estratégia de promoção da saúde pode contribuir para prevenção da violência.

Este trabalho foi produzido utilizando a metodologia de revisão bibliográfica utilizando dados retirados de artigos, com o levantamento virtual das produções acadêmicas por meio de bases de dados como: Scielo, Lilacs, Bireme e de revistas científicas. ${ }^{(4)}$

\section{CARACTERIZAÇÃO DE VIOLÊNCIA}

As diversas definições de violência e suas mais variadas formas vêm sendo mencionadas nos últimos anos como um grave e relevante problema em diversos países, em virtude de sua tendência crescente, inclusive no Brasil. ${ }^{(5)}$

A Organização Mundial da Saúde define a violência como o uso de força física ou poder, em ameaça ou na prática, contra si próprio, outra pessoa ou contra um grupo ou comunidade que resulte ou possa resultar em sofrimento, morte, dano psicológico, desenvolvimento prejudicado ou privação. ${ }^{(6)}$ Encontrando-se ainda outras definições que vão desde ações com o uso da força que vão contra a natureza de alguém, coação, constrangimento, tortura, brutalização, intimidação, amedrontamento, aterrorização, entre outros atos que vão contra a vontade com ou sem abuso físico. ${ }^{(7)}$

Volume 1, Número 1 - Abril, 2015. 
A violência aparentemente é algo vivido pelo homem desde sua existência, como descrito em estudos sobre a idade da pedra, ou até antes desta, como nas lendas e na mitologia. Mas a preocupação quanto a este tema, e o questionamento quanto ao problema que esta violência acarreta é bem recente, mostra-se a partir do século XIX. O comportamento biológico é apontado como a primeira raiz da violência humana, sendo o homem um ser contraditório, incoerente, dotado de instintos além da razão. Os autores avançam dentro de uma análise mais ampla quando apontam como outra causa a estrutura da sociedade dividida em classes, baseada no processo de opressão e espoliação de uma classe sobre a outra. ${ }^{(8)}$

A violência da desigualdade social existe, não por ser uma decorrência natural do viver em sociedade, mas porque ele aparece em condições históricas específicas. A partir do período colonial, no Brasil, houve "a catequização dos índios" que funcionou como um adestramento desta população à imposição da cultura portuguesa. E para que isso se fizesse possível foi usado todo tipo de violência, em que os portugueses exploravam a força de trabalho indígena, seus corpos e alienando suas consciências, uma fusão da violência física, sexual e psíquica. Em seguida, outro grupo, os escravos, domados aos seus senhores, refletindo uma realidade não menos cruel: foram expostos às maiores crueldades, tendo ignorada a sua condição de seres humanos. ${ }^{(8)}$

E assim, foram gerados os filhos do Brasil, da miscigenação de todos estes indivíduos, incluído os portugueses, filhos estes da violência e muitas vezes dos estupros. Já no próprio ventre, as crianças negras iniciavam uma vida de violenta opressão, pois a maternidade em muitos casos era uma arma contra a fome e a miséria. A negra, após o parto, era valorizada como ama de leite e alugada, sendo tratada com menos violência, passava a morar em uma casa melhor, a fazer os serviços mais leves. ${ }^{(8)}$

No século $X X$, foi constatado que os problemas relacionados à violência continuavam sem muitas explicações precisas e que isso prosseguiu até os dias de hoje. A sociedade brasileira enfrenta algumas situações de violência como o crescimento da delinquência urbana e de homicídios dolosos, a emergência da criminalidade organizada, em particular o tráfico internacional de drogas. A cada dia a mídia relata ainda mais a violência urbana e o envolvimento de jovens e adolescentes no narcotráfico. ${ }^{(8)}$

No Brasil, a criminalidade entre jovens é espantosa, haja vista suas participações no tráfico de drogas e nas ações criminosas em geral. Jovens perdidos, sem referência e sem formação adequada, transgridem as regras como um todo, e o que se reflete no mapa da violência (2011), mostrando que desde o ano 2000 , a violência homicida ocupa a terceira posição na causa de óbitos no país, além de serem responsáveis pela expressiva quantidade de internações hospitalares. ${ }^{(9)}$

Num recorte para as agressões interpessoais, destacam-se os atos de violência impetrados no âmbito doméstico e, em específico, contra mulheres, idoso e crianças. Estudos conduzidos em serviços de saúde sobre a violência contra a mulher demonstraram sua elevada prevalência, 
variando de $30 \%$ a $60 \%$ a proporção de mulheres que relataram terem sido vítimas de violência doméstica de natureza emocional, física ou sexual ao menos uma vez na vida. ${ }^{(10)}$

A expressão violência contra a mulher refere-se a situações diversas quanto aos atos e comportamentos cometidos: violência física, assassinatos, violência sexual e psicológica cometida por parceiros (íntimos ou não), estupro, abuso sexual de meninas, assédio sexual e moral (no trabalho ou não), abusos emocionais, espancamentos, compelir a pânico, aterrorizar, prostituição forçada, coerção à pornografia, o tráfico de mulheres, o turismo sexual, a violência étnica e racial, a violência cometida pelo Estado, por ação ou omissão, a mutilação genital, a violência e os assassinatos ligados ao dote, violação conjugal, violência tolerada perpetrada pelo Estado etc. ${ }^{(11)}$

A violência contra a mulher inclui, ainda, por referência ao âmbito da vida familiar, além das agressões e abusos já discriminados, impedimentos ao trabalho ou estudo, recusa de apoio financeiro para a lida doméstica, controle dos bens do casal e/ou dos bens da mulher exclusivamente pelos homens da casa, ameaças de expulsão da casa e perda de bens, como forma de coerção ou punição por comportamentos que a mulher tenha adotado. ${ }^{(12)}$

Outra forma de violência a ser ressaltada é o assédio moral. Este é definido como sendo atos cruéis e desumanos que caracterizam uma atitude violenta e sem ética nas relações de trabalho. Trata-se da exposição de trabalhadoras e trabalhadores a situações vexatórias, constrangedoras e humilhantes durante o exercício de sua função. É o que chamamos de violência moral. Esses atos visam humilhar, desqualificar e desestabilizar emocionalmente a relação da vítima com a organização e o ambiente de trabalho, o que põe em risco a saúde, a própria vida da vítima e seu emprego. A violência moral ocasiona desordens emocionais, atinge a dignidade e identidade do ser humano, altera valores, causa danos psíquicos, interfere negativamente na saúde, na qualidade de vida e pode até levar à morte. ${ }^{(13)}$

Já a violência doméstica pode ter início de forma lenta e silenciosa, que progride em intensidade e consequências. Constando-se que a grande maioria são geralmente parceiros, cônjuges com idade a partir de 35 anos, baixa escolaridade, da raça branca e com emprego fixo. A violência, em suas primeiras manifestações, não lança mão de agressões físicas, mas passa a limitar a liberdade individual da vítima, avançando para o constrangimento e humilhação. ${ }^{(14)}$

A literatura aponta os pais, padrastos e vizinhos como os principais responsáveis pelos casos de violência sexual. $\mathrm{O}$ abuso cometido por pessoas conhecidas e de confiança distorce a realidade e a visão de mundo da criança, uma vez que o ambiente onde ela poderia sentir-se segura passa a ser o palco privilegiado para o agressor. As ameaças físicas, verbais e até por armas de fogo não podem ser enfrentadas por estas crianças ou adolescentes e contribuem para o descrédito quanto a uma concepção de vida e mundo socialmente mais justos. ${ }^{(15,16)}$

A violência contra idosos no âmbito familiar é considerada como a mais frequente forma de agressão. Estudos demonstram que $90 \%$ dos casos de maus-tratos e negligência contra as pessoas

Volume 1, Número 1 - Abril, 2015. 
acima de sessenta anos ocorrem nos lares. As pesquisas revelam que cerca de dois terços dos agressores são filhos, cuidadores e cônjuges dos idosos vitimizados. ${ }^{(17)}$

Qualquer membro da família pode se tornar, em determinadas circunstâncias, vítima ou autor de violência. As crianças, adolescentes e os idosos, entretanto, mais indefesos e dependentes da família e da sociedade, são as principais vítimas desse tipo de violência, tanto em extensão como em gravidade dos danos e suas consequências. ${ }^{(18)}$

A associação entre o uso de álcool e o exercício da violência são na maioria das vezes agentes desinibidores que facilitam a ocorrência destes eventos $(19,20)$. Mas esse uso abusivo de bebidas alcoólicas nos fins de semana, associado a fortes pressões socioeconômicas, estilo educacional rígido e punitivo, ambiente sociocultural complexo e exigente, com frequência, conduz essas famílias a comportamentos violentos, impulsionados e modulados por esses mesmos fatores. ${ }^{(21)}$

Perante o que foi exposto é importante que se tenha em vista que independente da tipologia da violência, ela ocorre devido a circunstâncias e um contexto sócio-histórico que pode ser modificado à luz de estratégias que visem a prevenção da violência, sugerindo-se a promoção de saúde.

\section{PROMOÇÃO DA SAÚDE}

A promoção da saúde representa uma estratégia eficaz para enfrentar os múltiplos problemas de saúde que afetam as populações humanas neste final de século. Partindo de uma concepção ampla e complexa do processo saúde-doença e de seus determinantes, sugere a articulação de saberes empregados em saúde juntamente com os populares, através da mobilização de recursos institucionais e comunitários, públicos e privados, para seu enfrentamento.

$\mathrm{Na}$ divulgação da Carta de Ottawa ${ }^{(22)}$, um dos documentos fundadores da promoção da saúde, a conceituação está inscrita a um conjunto de valores que entre eles estão a qualidade de vida, saúde, solidariedade, eqüidade, democracia, cidadania, desenvolvimento, participação e parceria, entre outros. Referenciando-se a combinação de estratégias como as ações do Estado (políticas públicas saudáveis), da comunidade, de indivíduos (desenvolvimento de habilidades), do sistema de saúde (reorientação) e de parcerias entre os diversos setores. Isto é, implica na idéia de responsabilização múltipla pelo surgimento de conflitos, seja pelas soluções propostas para os mesmos.

A promoção da saúde vem sendo interpretada, de um lado, como reação ao uso excessivo de medicalização na vida social e, de outro, como uma resposta harmoniosa de diversos recursos técnicos e posições ideológicas. Segundo estudiosos seu significado foi mudando, passando a representar, mais recentemente, um enfoque político e técnico em torno do processo saúde-doençacuidado. ${ }^{(23)}$

Volume 1, Número 1 - Abril, 2015. 
Um dos pioneiros a definir as tarefas essenciais da medicina, dentre elas a promoção da saúde, afirma que a saúde se promove proporcionando condições de vida dignas, boa organização do trabalho, educação, cultura física e formas de descanso e lazer. Para tanto, sugeria a realização do trabalho coordenado entre políticas inter-setoriais e empresariais. ${ }^{(24)}$

Autores que avaliam o conceito de promoção da saúde no modelo de prevenção. No nível da prevenção primária, dizem de medidas destinadas ao desenvolvimento da saúde em geral, através da proteção específica ao homem. O que torna a educação em saúde um elemento primordial para esse objetivo. Os autores reforçam que os procedimentos para a promoção da saúde incluem um bom padrão de atendimento às necessidades da personalidade, o aconselhamento e educação adequada, em atividades individuais ou coletivas, com extensão ao resto da família. ${ }^{(23)}$

Tratando-se de um modelo de promoção da saúde focado na individualidade, com projeção para os grupos comunitários. Descrevendo-se a promoção da saúde como atividades dirigidas à transformação dos comportamentos dos indivíduos, centrando nos seus estilos de vida, e ampliando para o ambiente das culturas. Concentrando-se em componentes educativos, primariamente relacionados com riscos comportamentais passíveis de mudanças, que estariam em parte, sob o controle dos próprios indivíduos. Por exemplo, o hábito agressivo e o de fumar, obesidade, atividades físicas e a direção perigosa no trânsito. Nessa abordagem, fugiriam do âmbito da promoção da saúde todos os fatores que estivessem fora do controle dos indivíduos. ${ }^{(25)}$

Ainda sustenta-se o conceito de promoção no entendimento que a saúde é produto de amplos aspectos relacionados com a qualidade de vida; boas condições de trabalho; oportunidades de educação ao longo de toda a vida; ambiente físico limpo; apoio social para famílias e indivíduos; estilo de vida responsável; e um espectro adequado de cuidados de saúde. Suas atividades estariam, então, mais voltadas ao coletivo e ao ambiente, compreendido num sentido amplo, de ambiente físico, social, político, econômico e cultural. ${ }^{(25)}$

Seguindo-se essa linha de pensamento, o papel das políticas públicas que se fortalecem nas estratégias de promoção de saúde, seria o favorável ao desenvolvimento da saúde no fortalecimento das capacidades dos indivíduos e suas comunidades. Assim, pautada na Carta de Ottawa, o processo envolve a capacitação da comunidade para atuar na melhoria da sua qualidade de vida e saúde, incluindo uma maior participação no controle deste processo. ${ }^{(22)}$ Incutindo-se responsabilidade aos indivíduos e à comunidade pela sua própria saúde.

Verificando-se que o conceito de promoção da saúde vem sendo elaborado por diferentes atores, em equipes interdisciplinares, em diferentes contextos e formações sociais. Com atenção inclusive, que de forma paradoxal, voltada para políticas públicas em saúde, com efeitos que impulsionaram a economia urbano-industrial ao longo do século $\mathrm{XX}$, apresentando desigualdades sociais, danos ambientais irreparáveis e até ambientes sociais mórbidos geradores de sociopatias e psicopatias (violência, drogas etc.).

Volume 1, Número 1 - Abril, 2015. 
Nessa perspectiva proporcionar saúde significa, além de evitar doenças e prolongar a vida, assegurar meios e situações que ampliem a qualidade da vida, ou seja, ampliem a capacidade de autonomia e o padrão de bem-estar, através de valores socialmente definidos e compartilhados. Representando, assim, uma nova e mais adequada redistribuição de direitos e responsabilidades entre o Estado e a sociedade.

\section{DISCUSSÃO}

Relacionada aos resultados alcançados por movimentos sociais de direitos humanos, de direito da criança, da mulher e do adolescente, e também de outros métodos mais amplos e presentes em toda a sociedade, como o da consolidação democrática. Esse estudo buscou especificar situações de violência com o intuito de gerar conhecimento, valorizando o mérito da promoção de saúde enquanto espaço para prevenção da violência.

Pesquisas ${ }^{(26)}$ estimam que, para 10.000 pessoas que morrem no trânsito, 50.000 resistem com sequelas, cujos encargos de tratamento e reabilitação são altos. A Associação Brasileira de Crianças Abusadas e Negligenciadas informa que, em 1992, no Brasil, houve cerca de 4,5 milhões de crianças vítimas de violência. Corroborando os estudos ${ }^{(26,27)}$ que ostentam, em abordagens espacialmente localizadas, que $33 \%$ das crianças e adolescentes relatam o tormento de atos violentos nas suas relações com os pais.

Um estudo realizado num hospital de Cali, na Colômbia, aponta que 41/1.000 dos pacientes pediátricos são atendidos com diagnóstico de problemas de maus-tratos. $O$ autor ${ }^{(28)}$ relata também uma pesquisa realizada num hospital de Medelim, na Colômbia, para os anos de 1987 e 1988, em que foi comprovado que $73,8 \%$ das crianças maltratadas que buscaram os serviços são pertencentes de famílias que sobrevivem com menos de um salário mínimo, juntando-se, assim, a violência estrutural e a violência doméstica.

$O$ atendimento imediato às vítimas e todo o esforço de reabilitação e readaptação representam, hoje, em países como o Brasil, uma sobrecarga dos serviços de emergência dos hospitais públicos, dos centros especializados e dos institutos médico-legais, indicando a necessidade de adequação de recursos humanos e de equipamentos ao crescimento da demanda. Não se pode omitir, também, um efeito por vezes irradiado, por vezes direto, que a violência provoca sobre a estrutura e o funcionamento dos serviços públicos de saúde, sobretudo quando os conflitos por eles atendidos afetam os profissionais, pelo amedrontamento, pelas ameaças, pelos danos físicos e/ou psicológicos.

Um estudo sobre violência contra as mulheres ${ }^{(29)}$ informa que $35 \%$ das mulheres que recorrem aos hospitais nos Estados Unidos apresentam indícios de maus-tratos. Acrescenta, também, que estudos realizados nesse país demonstram que as mulheres maltratadas estão quatro Volume 1, Número 1 - Abril, 2015. 
a cinco vezes mais expostas a tentativas de suicídio, depressão, dores crônicas e uso de substâncias psicoativas. Os maus-tratos propiciam gravidez e maternidade com risco de morte tanto para o bebê quanto para a gestante, e duplicam o risco de aborto e de nascimento com baixo peso.

No Canadá quanto a violência contra o idoso ${ }^{(30)}$, estima-se que de $4 \%$ a $10 \%$ destes sofrem uma ou mais formas de abuso, sendo as mais frequentes de origem financeira $(12,5 \%)$, verbal $(1,4 \%)$ ou física $(0,5 \%)$. Através da síntese dos dados de 30 investigações, o Congresso Americano também conclui que cerca de $4 \%$ da população de idosos do país (mais de 1 milhão de pessoas) são atropelados física, emocional e financeiramente por familiares e conhecidos.

No Brasil, utilizando-se dos dados de mortalidade da população de mais de 60 anos, altas taxas de causas externas estão vinculadas a atropelamentos e quedas. A situação do serviço público de saúde e a proporção dos que recebem um salário mínimo de aposentadoria (73\%) sugerem a dimensão da tragédia(31).

Já quanto aos aspectos da infância e juventude pesquisadores do Claves ${ }^{(32,33)}$ analisam a situação de famílias e crianças que vivem nas ruas como uma expressão da violência advinda das estruturas políticas, combinada com a cólera dos conflitos familiares. Do ponto de vista mais restrito da saúde, relatam a elevada frequência de invalidez entre homens, resultantes de ferimentos por armas de fogo e arma branca durante agressões em brigas de rua, além de sequelas de enfermidades como poliomielite e diabetes. A maioria menciona problemas mentais, desejo e tentativas de suicídio, bem como consumo de substâncias psicoativas, relacionados à sua situação de vida miserável. Num total de 63 famílias ouvidas houve relato de 14 homicídios de familiares $(22 \%)$, sendo $9(14,3 \%)$ referentes a menores de 18 anos.

A reflexão das questões acima revela a amplitude que a violência coloca para a Saúde Pública. Em síntese, além dos efeitos diretos e indiretos, físicos e simbólicos, sobre a população, os problemas classificados por tipos diferentes de violência, congestionam serviços de saúde, aumentam os custos integrais da atenção e afetam a qualidade da cobertura do serviço público de saúde.

A perspectiva das políticas públicas saudáveis, incluindo a estratégia de promoção de saúde, distingue-se e ultrapassa em abrangência as ações ambientais da saúde pública tradicional e, mesmo, as políticas urbanas de expansão de serviços e bens de consumo coletivo. Implica uma abordagem mais complexa, devendo ser compreendida como uma (re)formulação inovadora tanto do conceito de saúde quanto do conceito de Estado (e, portanto, de política pública) e de seu papel perante a sociedade, inclusive no trato com a questão da violência.

Aspectos que corroboram Gutierrez ${ }^{(34)}$ quando define promoção da saúde como o conjunto de ações, processos e recursos, de ordem institucional, governamental ou da cidadania, orientados a propiciar a melhoria das condições de bem-estar, que propiciam o desenvolvimento de competências favoráveis ao cuidado da saúde e o desenvolvimento de estratégias que permitam à

Volume 1, Número 1 - Abril, 2015. 
população maior controle sobre sua saúde, apropriado à realidade latino-americana, que agrega ao papel da comunidade a promoção da saúde.

A nova concepção de saúde importa uma visão afirmativa, que a identifica como bem-estar e qualidade de vida, e não simplesmente com ausência de doença. A saúde deixa de ser um estado estático, biologicamente definido, para ser compreendida como um estado dinâmico, socialmente produzido. Nesse marco, a intervenção visa não apenas diminuir o risco de doenças, mas aumentar as chances de saúde e de vida, acarretando uma intervenção multi e intersetorial sobre os chamados determinantes do processo saúde-enfermidade: eis a essência das políticas públicas saudáveis quando coloca à disposição da violência estratégias a luz da promoção de saúde.

\section{CONCLUSÃO}

A Promoção da saúde pode contribuir amplamente enquanto auxiliar na luta contra a violência, principalmente ao que tange a construção de ações e políticas voltadas para a prevenção. A promoção da saúde instaura-se como forma de ação preventiva mais eficaz que pode trabalhar o sujeito de dentro para fora, como ser no mundo, não esquecendo de atuar no aumento de estudos direcionados para estratégias e planejamento dos recursos disponíveis para atender as necessidades que surgirão ao longo do tempo.

Por todos esses aspectos, a prevenção da violência para o setor de saúde traz à luz algumas considerações básicas. Primeiramente, devemos direcionar nossas energias para o pleno exercício da democracia e na luta por justiça social, atuando sobre a pobreza que é uma das causas mais diretas da violência. Por outro lado, devemos trabalhar observando as questões multifatoriais sobre o tema, bem como incentivar de maneira intersetorial, multiprofissional a sociedade civil na luta pelo direito à dignidade e à cidadania. Em virtude do que foi mencionado, podemos dizer que os eventos violentos não são uma fatalidade, não são acidentais e menos ainda falta de sorte, eles podem ser prevenidos e evitados. E, consequentemente, pode-se construir e viver numa sociedade com menos violência.

O estreitamento deste estudo que focou nas principais formas de violência, devido ao tema ser bastante amplo, deixa lacunas a serem preenchidas por pesquisadores interessados na área, que é uma das mais importantes para a construção do sujeito social, o que sustenta a base de uma comunidade onde se possa viver com dignidade e qualidade de vida.

\section{REFERÊNCIAS}

1. MINAYO, M.C. S. A violência social sob a perspectiva da saúde pública. Cadernos de Saúde Pública, Suple1, №10, p.7-18,1994.

Volume 1, Número 1 - Abril, 2015. 
2. CASAGRANDE, M. C., PERUZZOLO, A. C. O fenômeno da violência e sua relação com meios de comunicação, comunicação humana e estado. Marília, 2012;10:237-255.

3. ZAFFARONI. O inimigo no Direito Penal. Trad. Sérgio Lamarão. Rio de Janeiro: Revan, 2007.

4. MARCONI, M. A.; LAKATOS, E. M. Técnicas de pesquisa: planejamento e execução de pesquisas, amostragens e técnicas de pesquisa, elaboração, análise e interpretação de dados. 6 . Ed. São Paulo: Atlas, 2006, pg.71-75.

5. GUIMARAES, J. M. X. et al, Estudo epidemiológico da violência por arma branca no município de Porto Grande. Ciências \& saúde coletiva. Amapá, 2005;10(2):441-451.

6. CHAUÍ, M. Introdução à Filosofia. Porto Alegre: Ed. Bertand Brasil, 1999.

7. Violência e saúde: estudos científicos recentes, Rev Saúde Pública 2006;40(N Esp):112-20

8. World Health Organization. Global consultation on violence and health. Violence: a public health priority. Geneva: WHO; 1996 (document WHO/EHA/ SPI.POA.2).

9. DAHLBERG, L. L..; KRUG, E.G. Violence: a global public health problem. World Report on Violence and Health. Geneve: World Health Organization, 2002.

10. BRASIL. Ministério da Saúde. Sistema de informações sobre mortalidade. Disponível em: <http://tabnet.datasus.gov.br/tabdata/cadernos/mg.htm>.

11. SCHRAIBER, L.B. et al. Violência contra a mulher entre usuárias de serviços básicos de saúde da rede pública da grande São Paulo. Rev. Saúde Publica, 2007;41(3):359-367.

12. SOARES, B.M. Mulheres invisíveis: violência familiar e formações subjetivas. 1997. Tese (Doutorado) - Instituto Universitário de Pesquisas do Rio de Janeiro, Rio de Janeiro. 1997.

13. Cartilha Assédio Moral e Sexual no Trabalho. [acesso em 25/09/2014]. Disponível em: http://portal.mte.gov.br/data/files/8A7C812D3CB9D387013CFE571F747A6E/CARTILHAASSEDIO MORALESEXUAL\%20web.pdf

14. SILVA, L.L., COELHO, E.B.S., CAPONI, S.N.C. Violência silenciosa: violência psicológica como condição da violência física doméstica. Interface - Comunicação Saúde Educação, 2007;11:93-103.

15. COSTA, M.C.O. et al. O perfil da violência contra crianças e adolescentes, segundo registros de Conselhos Tutelares: vítimas, agressores e manifestações de violência. Ciência e Saúde Coletiva, Rio de Janeiro, 2007;12(5):1129-1141.

16. RIBEIRO, M.A.; FERRIANI, M.G.C.; REIS, J.N. Violência sexual contra crianças e adolescentes: características relativas à vitimização nas relações familiares. Cadernos de Saúde Pública, Rio de Janeiro, 2004;20(2):456-464.

17. SOUZA, E.R. Masculinidade e violência no Brasil: contribuições para a reflexão no campo da saúde de. Ciência \& Saúde Coletiva, 2005;10:59-70.

18. CASTILLO, M. M. A., CAUFIELD, C., GÓMEZ MEZA, M.V. Consumo de drogas y violência laboral en mujeres trabajadoras de Monterrey, N. L., México. Revista Latino-Americana de Enfermagem 2005;13:1164-1168.

Volume 1, Número 1 - Abril, 2015. 
19. ZILBERMAN, M. L.; BLUME, S. B. Violência doméstica, abuso de álcool e substâncias psicoativas. Revista Brasileira de Psiquiatria 2005;27 Supl II:S51-S55.

20. MELO, Z. M., CALDAS, M. T., CARVALHO, M. M. C., LIMA, A. T. Família, álcool e violência em uma comunidade da cidade do Recife. Psicologia em Estudo 2005;10:201-208.

21. JURGENSEN, G. Nadie se rebela. Salud Mundial, 46: 09. 1993.

22. WHO. Carta de Ottawa, pp. 11-18. In Ministério da Saúde/FIOCRUZ. Promoção da Saúde: Cartas de Ottawa, Adelaide, Sundsvall e Santa Fé de Bogotá. Ministério da Saúde/IEC, Brasília. 1986

23. LEAVELL, H R; CLARK, E.G. Medicina preventiva. Rio de Janeiro: McGraw-Hill do Brasil, 1976.

24. SIGERIST, H. E. The University at the Crossroad. New York: Henry Schumann Publisher, 1946.

25. SUTHERLAND, R.W. \& FULTON, M.J. Health promotion. In Sutherland \& Fulton. Health Care in Canada. Ottawa, 1992:161-181.

26. ASSIS, S. G. Quando Crescer é um Desafio Social: Estudo Sócio-Epidemiológico sobre Violência em Escolares em Duque de Caxias. Tese de Mestrado, Rio de Janeiro: Escola Nacional de Saúde Pública, Fundação Oswaldo Cruz. 1991.

27. DESLANDES, S. F. Prevenir e Proteger: Análise de um Serviço de Atenção aos Maus Tratos na Infância. Tese de Mestrado, Rio de Janeiro: Escola Nacional de Saúde Pública, Fundação Oswaldo Cruz. 1993.

28. AGUDELO, S. F. Violencia y/o Salud: Elementos Preliminares para Pensarlas y Actuar. Washington, DC: PAHO/OMS (Mimeo.) 1989.

29. HEISE, L. Violence against Women: The hidden health burden. Discusion paper prepared for the World Bank. Washington, DC.: World Bank. (Mimeo.) 1993.

30. WOLF, R. S. Maltrato en el anciano. In: Atención de los Ancianos: UmDesafío para los Noventa (E. Anzola-Pérez, ed.), Washington, DC: Opas. (no prelo) 1994.

31. MINAYO, M. C. S. (Org.). Os Limites da Exclusão Social: Meninos e Meninas de Rua no Brasil. São Paulo: Hucitec. 1993.

32. MINAYO, M. C. S. \& ASSIS, S. G. Violência e saúde na infância e adolescência: uma agenda de investigação estratégica. Saúde em Debate, 1993;39:58-63.

33. MINAYO, M. C. S. \& SOUZA, E. R. Violência para todos. Cadernos de Saúde Pública, 1993;9: 65-78.

34. GUTIERREZ, M. et al. Perfil descriptivo-situacional del sector de la promoción y educación en salud: Colombia. In Aroyo HV e Cerqueira MT (eds.), 1996. La Promoción de la Salud y la Educación para la Salud en America Latina: un Analisis Sectorial. Editorial de la Universidad de Puerto Rico. 114 pp.

Volume 1, Número 1 - Abril, 2015. 